\title{
Studies on Mechanical and End-Use Properties of Natural Rubber Filled with Snail Shell Powder
}

\author{
Isaac Ogbennaya Igwe, Augustina Adanna Ejim
}

Department of Polymer and Textile Engineering, Federal University of Technology, Owerri, Nigeria.

Email: izikigwe@yahoo.com

Received February $21^{\text {th }}, 2011$; revised March $21^{\text {th }}, 2011$; accepted April $2^{\text {nd }}, 2011$.

\begin{abstract}
A series of natural rubber-snail shell powder vulcanizates were compounded on a two-roll mill, and moulded on a compression moulding machine. The mechanical and end-use properties of the natural rubber vulcanizates were investigated at snail shell powder contents, 0 to $20 \mathrm{pphr}$. The snail shell powder was characterized for filler properties and sieved to 0.075 , and $0.30 \mu \mathrm{m}$ particle sizes. Carbon black was used as the reference filler. Results showed that the tensile strength, modulus, elongation at break, and resilience of the rubber vulcanizates were not enhanced on addition of snail shell powder. The hardness of the rubber vulcanizes were marginally increased at high snail shell powder content. However, the specific gravity of the rubber vulcanizates showed increases with increase in snail shell powder content. At a filler content above 5 pphr, snail shell powder exhibited good flame retardant property in the vulcanizates. The swelling indices of snail shell powder $(0.075 \mu \mathrm{m})$ filled natural rubber were generally good, and better than those of snail shell powder $(0.30 \mu \mathrm{m})$ filled natural rubber. Carbon black was found to show more property improvement for the natural rubber vulcanizates when compared to snail shell powder. Although the mechanical properties of snail shell powder filled natural rubber vulcanizates were not good, there were improvements in the end-use properties, an indication that snail shell powder could still find utilization in the rubber industry where specific end-use property of a rubber product is required.
\end{abstract}

Keywords: Snail Shell Powder, Natural Rubber, Filler, Vulcanizates, Mechanical Properties

\section{Introduction}

Polymers such as polyolefins and elastomers are widely exploited but are often not used as neat polymers. These polymers are frequently compounded with natural minerals so as to improve their properties, as well as to reduce cost. In the vulcanization of rubber, carbon black is the main filler in use. The properties impacted by carbon black to the rubber compound depend on several factors such as particle size, structure, physio-chemical nature of the surface area, and particle porosity. However, because of the origin of carbon black from petroleum, carbon black causes pollution, and gives the rubber a black colour. The filler is also costly [1,2]. Thus, investigations are now on, aimed at finding suitable reinforcing agents to replace carbon black in the compounding of rubber products. Sepiolite, Kaolin, and precipitated silica were commonly used as reinforcing agents. However, their reinforcing properties are lower than those of carbon black. Because of their inorganic origin, these mineral fillers are not compatible with polymer matrices. The particle size, structure, and surface characteristics are important factors that are considered in determining the reinforcing ability of a filler to rubber compounds. The particle size is especially important because a reduction in particle size provides a greater surface area [3].

Thus, the use of talc, nano- $\mathrm{ZnO}$, nano- $\mathrm{CaCO}_{3}$, and nano- $\mathrm{Al}_{2} \mathrm{O}_{3}$ as substitutes for carbon black in rubber compounding has been suggested [4]. These fillers have small particle sizes and exhibit superior physical and mechanical properties in the vulcanizates when compared to the conventional micrcomposites. They also offer new techniques, and business opportunities in the rubber industry.

Different materials have been used to reinforce natu$\mathrm{ral} / \mathrm{synthetic} \mathrm{rubber}$ and are reviewed below. Arroyo et al [1] studied the use of ctadecylamine modified montmorillonite as substitute for carbon black in natural rubber (NR) compounds. The organo clay was reported to improve the strength of the natural rubber without having any reduction in the elasticity of the material. Zang et al. [5] studied the flammability of montmorillonite (MMT) 
/SBR nancomposites and reported that the maximum heat release rate (HRR) of SBR decreased from 1987 to 1442 $\mathrm{KW} / \mathrm{m}^{2}$ with the introduction of nanclay (20 pphr). The reinforcing effects of coal shale-based fillers on natural rubber were studied by Zhao and Xiang [6]. In this study, two kinds of coal shale were micro cracked, burned, and modified by epoxidaton with natural rubber (ENR), and then used as reinforcing fillers for natural rubber (NR). Result showed that the ultra micro coal-shale powder was a good filler for NR.

The use of clay in producing butadiene rubber (BR) nan ${ }^{\circ}$ Composite was reported by Kim et al. [7]. The tensile and tear strengths of BR/Cloisite 2OA (clay) composites were 4.4 times, and 2 times greater than that of unfilled BR, respectively. The rebound resilience, compression set, and abrasive resistance of BR/Cloisite 2OA was approximately twice larger than that of BR.

Yang et al. [8] investigated the influence of graphite particle size, and shape on the properties of acrylonitrile butadiene rubber (NBR) at 20, 40, and 60 pphr filler contents. It was found that the graphite having the smallest particle size possessed the best reinforcing ability, while the largest graphite particles imparted the lowest function coefficient of the composites among four fillers investigated. Anserifer et al. [9] studied the properties of natural rubber reinforced with synthetic precipitated amorphous white silica nanofiller. The hardness, tensile strength, and compression set were improved when the filler was incorporated into the rubber. However, the tear strength, elongation at break, and cyclic fatigue life were adversely affected. The effect of recycled rubber powder (RRP) on tensile properties and swelling behaviour of natural rubber (NR) compounds was investigated in the concentration range, 0 to $50 \mathrm{pphr}$ by Ismail et al. [10]. It was reported that increasing the RRP content produced natural rubber compounds that have better resistance to swelling and lower the elongation at break. However, the tensile stress M100 (stress at 100\% elongation) increased slightly.

Osman et al. [11] studied the effect of maleic anhydride- grafted polypropylene (MAPP) on the properties of recycled newspaper (RNP) filled polypropylene (PP)/natural rubber (NR) composites and reported that the incorporation of MAPP reduced the water uptakes of the composites. The effects of partial or complete replacement of carbon black (CB) and silica on the properties of paper sludge (PS) filled natural rubber composites were elucidated by Ismail et al. [12]. PS/silica filled natural rubber composites was reported to exhibit lower maximum torque, tensile properties and fatigue life compared to the PS/CB filled natural rubber composites. Sobhy and Tamman [13] in their studies found that the tensile strength of wheat husk fibres (WHFS)/ethylene- propylene-diene terpolymer (EPDM) composites was decreased as the filler content increased.

The use of agricultural by-products to reinforce natural rubber has similarly received the attention of researchers. Such agricultural by-products investigated included banana peel, rice husk, spent mango, bean seed skin and groundnut shell [14], cocoa pod and rubber seed shell [15], and short pine apple leaf fibre [16]. These agricultural by-products exhibited varying performance characteristics on natural rubber compounds.

In the present study, the use of snail shell powder as a filler in compounding natural rubber is reported. The snail shell powder was sieved to two particle sizes namely, 0.075 , and $0.30 \mu \mathrm{m}$. Snail shell powder content of 0 to 20 pphr were used for the purpose of the study. Carbon black was used as the reference filler. The use of snail shell powder in reinforcing natural/synthetic rubber had not been reported in the scientific literature to our knowledge. However, the industrial potential of reinforcing polypropylene, a thermoplastic polymer with snail shell powder was reported by Igwe [17]. Snail shell is a domestic waste and presently, does not have any known domestic/industrial applications in our locality. It could be found littering dustbins in our big cities and farm yards in villages.

\section{Materials and Methods}

Natural rubber and other vulcanizing agents such as zinc oxide, anti-oxidant (TMQ), stearic acid, accelerator (TBBS), soluble sulphur, and carbon black were kindly supplied by Dunlop PLC, Lagos, Nigeria. Linseed oil was purchased from a chemical store at Aba, Nigeria. Snail shell, from which snail shell powder was produced, was collected lcally within Owerri Metropolis, Nigeria. The snail shell powder was sieved to two particle sizes, namely, 0.075 and $0.30 \mu \mathrm{m}$, respectively. Snail shell consists essentially of calcium carbonate in a matrix of protein [18]. The snail shell powder which was used as a filler in this study was characterized for weight loss on ignition (ASTM D 1509, 1983), moisture content (ASTM D 1510, 1983), and oil absorption (BS 3483, Part B7) according to standard prcedures.

\subsection{Preparation of Natural Rubber Vulcanizates}

Table 1 gives the ingredients used in compounding natural rubber. The ingredients are arranged in the order in which they were used during the compounding prcess. A two-roll mill was used in the compounding prcess. After compounding, samples were obtained, coded accordingly, and prcessed further by curing.

\subsection{The Curing Prcess}

Each rubber vulcanizate produced was placed in a rectan- 
Table 1. Compounding recipe (pphr).

\begin{tabular}{cc}
\hline Materials & Contents (pphr) \\
\hline Natural rubber & 100 \\
Stearic acid & 3 \\
Zinc oxide $(\mathrm{ZnO})$ & 3 \\
${ }^{\mathrm{a}} \mathrm{TMQ}$ & 1 \\
${ }^{\mathrm{b}} \mathrm{TBBS}$ & 1 \\
Soluble sulphur & 1.8 \\
Linseed oil & 2 \\
Filler (snail shell powder) & Variable $(2,5,7,10,15,20)$ \\
\hline
\end{tabular}

gular shaped mould and introduced into a compression moulding machine for $40 \mathrm{~min}$ at $140^{\circ} \mathrm{C}$, and pressure of $1800 \mathrm{psi}$ to produce a rectangular sheet measuring $7.40 \times$ $23.10 \mathrm{~cm}$. After curing, samples were produced and set for property testing. Natural rubber vulcanizates of snail shell powder, particle sizes, 0.075 , and $0.30 \mu \mathrm{m}$ were prepared in this study for subsequent investigations.

\subsection{Tests on Vulcanized Natural Rubber}

The cured sheets were subjected to conditioning for $24 \mathrm{hr}$ at room temperature, $32^{\circ} \mathrm{C}$. The following tests were carried out on the rubber samples using standard prcedures: tensile strength, tensile modulus, elongation at break, hardness, resilience, flame retardancy, specific gravity, and swelling index.

\section{Results and Discussion}

\subsection{Analysis of Snail Shell Powder}

Some characteristics of snail shell powder (SSP) have been determined alongside those of carbon black (CB) which served as the reference filler in this study, and are shown in Table 2.

The higher weight loss on ignition recorded for SSP when compared to $\mathrm{CB}$ is an indication that $\mathrm{CB}$ is more resistant to thermal effect. The effectiveness of a filler may be measured by the carbon content. The higher the value, the greater is the reinforcing effect [16]. Table 2 shows that carbon black lost the least amount of moisture on heating. The oil absorption values for the fillers (Table 2) indicates that the aggregate structure of carbon black is only greater than that of snail shell powder of particle sizes, 0.30 and $0.075 \mu \mathrm{m}$ by about 3.56 and 4.18 $\mathrm{kg}$ respectively. It is well known that $\mathrm{CB}$ consists of modular subunits called particles by ASTM classification [15]. The similarity in the oil absorption values for the fillers may be an indication that SSP of particle sizes, 0.30 and $0.075 \mu \mathrm{m}$ have structures that may be closely related to $\mathrm{CB}$ in the sense considered above, and therefore may produce similar effects in the vulcanizates.

\subsection{Properties of Natural Rubber Vulcanizates}

Figure 1 shows that the tensile strength of SSP filled natural rubber showed initial increases in tensile strength
Table 2. Some characteristics of snail shell powder.

\begin{tabular}{ccc}
\hline Parameter & SSP & CB \\
\hline Loss on ignition $(\%)$ & 43.33 & 91 \\
Moisture content $(\%)$ & 18.33 & 2.70 \\
Oil absorption $(\mathrm{kg})$ & $4.65(0.075 \mu \mathrm{m})$ & 8.83 \\
& $5.27(0.30 \mu \mathrm{m})$ & - \\
\hline
\end{tabular}

with increases in SSP content upto $2 \mathrm{pphr}$; after which decreases in tensile strength with increases in SSP content was observed.

The decrease in tensile strength of rubber vulcanizates with increase in filler contents has been reported by Ismail et al. [2], who working with oil palm wood flour reinforced epoxidized natural rubber found that the tensile strength of rubber vulcanizates decreased with increases in wood flour content. On the contrary however, Mishra and Shimpi [19] reported general increases in tensile strength of nano- $\mathrm{CaCO}_{3}$ filled SBR with increases in filler content until maximum tensile strength was reached, after which the tensile strength decreased with any further increase in filler content. The tensile strengths of rubber vulcanizates filled with SSP, particle size, $0.075 \mu \mathrm{m}$ were in most cases smaller than that of unfilled natural rubber vulcanizates. Similarly, natural rubber filled with SSP of particle size, $0.30 \mu \mathrm{m}$ exhibited higher tensile strength than those filled with SSP, particle size, $0.075 \mu \mathrm{m}$ at filler contents below $18 \mathrm{pphr}$. This result is unexpected. Generally, the smaller the particle size of a filler, the greater is the tensile strength of the vulcanizates, and rice versa [2]. The better filler dispersion, and filler-matrix interaction are generally believed to be the two main factors responsible for the trend observed above.

The reference filler, $\mathrm{CB}$, showed steady and significant increases in the tensile strength of the vulcanizates, and which were in all cases higher than the tensile strength of SSP filled NR. As was pointed out earlier, the effectiveness of a filler may be measured by its carbon content. The higher the values, the greater the reinforcing ability. From the results of weight loss on ignition test, carbon black has more carbon content than SSP, and they might explain in part the better reinforcing ability exhibited by carbon black over SSP. It should be noted that tensile strength increase is a result of additional reinforcement of the polymer phase. The degree of reinforcement depends on the extent of polymer and filler interaction. In the present investigation, the interactive forces are envisaged to increase with carbon black content, and so, does the degree of reinforcement.

The poor strength property exhibited by snail shell powder could be attributed to the geometry of the filler. For irregularly shaped fillers, the strength of the compos- 


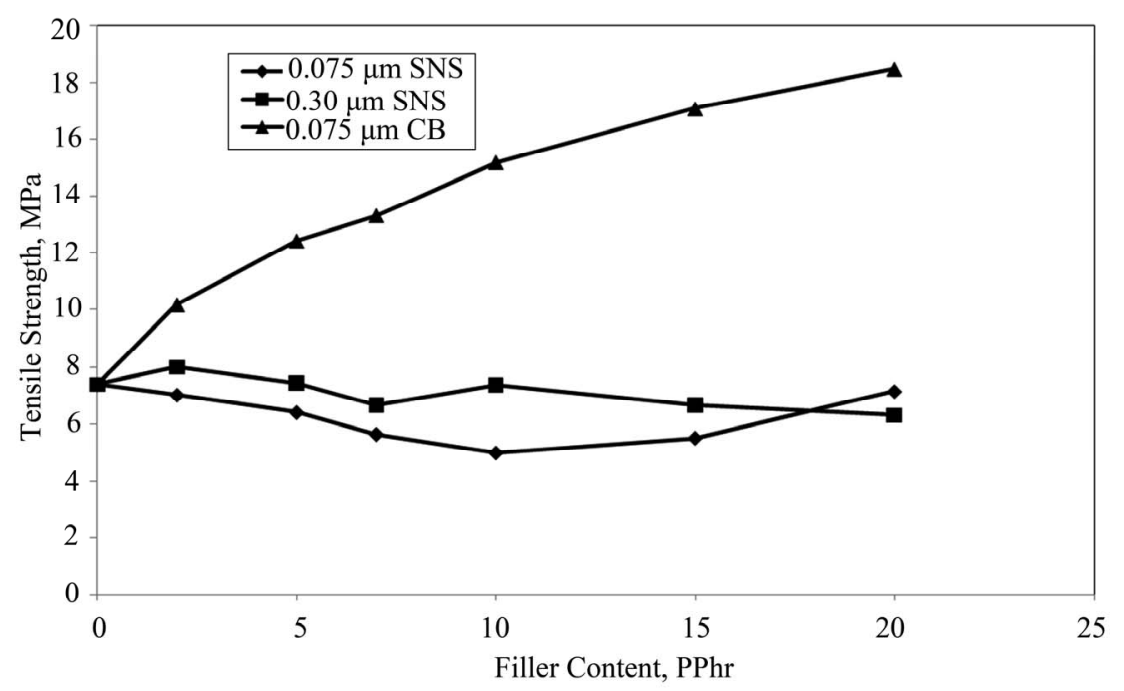

Figure 1. The effect of filler content and particle size on tensile strength of filled natural rubber.

ites decrease due to the inability of the filler to support stresses transferred from the polymer matrix [19].

The effects of filler content and particle size on the modulus of filled natural rubber vulcanizates are shown in Figure 2. The modulus of unfilled natural rubber vulcanizate is $1.84 \mathrm{MPa}$. It is evident from the figure that the modulus of snail shell powder filled natural rubber vulcanizates are always less than that of unfilled rubber vulcanizate, at all the filler contents and particle sizes investigated.

Figure 2 also shows a decrease in the modulus of filled rubber vulcanizates within the filler contents, 20 to $15 \mathrm{pphr}$. At a higher filler content, $20 \mathrm{pphr}$, the modulus increased again.

The modulus of carbon black filled natural rubber vulcanizate is observed to increase steadily with increasing carbon black content, and were in all cases higher than the ones of unfilled natural rubber vulcanizate, and snail shell powder filled natural rubber vulcanizates. These observations reveal that polymer matrix-filler interaction is an important factor controlling the modulus. It is well known that natural rubber forms a strong adsorptive bond with carbon black [20].

The surface activity is also an important factor indicating the extent of polymer filler interaction; with good polymer filler interaction, there could be increases in modulus. Based on this concept, carbon black has very high surface activity, which provided greater reinforcement in comparison with snail shell powder. The decrease in modulus of snail shell powder vulcanizates in the loading range studied may suggest that snail shell powder is not a good reinforcing material (filler) for natural rubber as the carbon black.

The decrease in the modulus of snail shell powder filled natural rubber observed in this study contrasted sharply with some previous reports on natural rubber vulcanizates. For example, Ismail et al. [10] who worked on oil palm wood flour reinforced epoxidized natural rubber reported a general increase in the modulus of the composites with increasing oil palm wood flour content. Similarly, Ahmad et al. [20] reported that at $100 \%$ elongation, polyethylene blends filled with silica and calcium carbonate increased with increasing filler content. However, Okieimen and Imanah [15] who studied powdered cocoa pod, and rubber seed shell filled natural rubber vulcanizates reported both increases, and decreases in the modulus of the rubber blends with increasing filler content.

The poor modulus observed for snail shell powder filled natural rubber in this study could again be attributed to poor rubber-snail shell powder interaction since stronger rubber-snail shell powder interaction would have increased the effectiveness of the stress transferred from the rubber matrix to snail shell powder particles dispersed in the rubber matrix and this would subsequently enhance the modulus of the vulcanizates.

In this study however, the more the incorporation of snail shell powder into natural rubber, the poorer the envisaged interaction between the two and hence, the observed decrease in modulus of the system with increasing filler content.

Figure 3 shows the effect of filler content, particle size, and type on elongation at break (EB) of vulcanized natural rubber. The EB of unfilled natural rubber valconizate is $85.85 \%$. A close examination of Figure 3 shows that the EB of carbon black, and snail shell powder (particle sizes, 0.075 and $0.30 \mathrm{~mm}$ ) filled natural rubber vulcanizates are always less than the EB of un- 


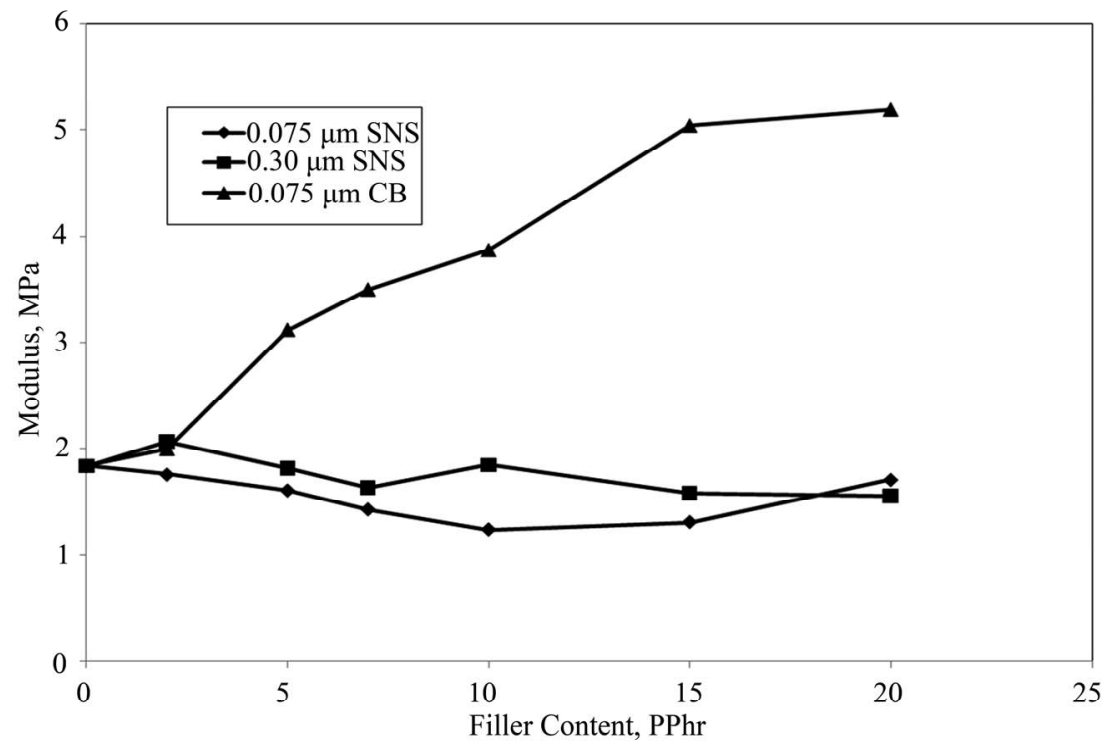

Figure 2. The effect of filler content and particle size on modulus of filled natural rubber.

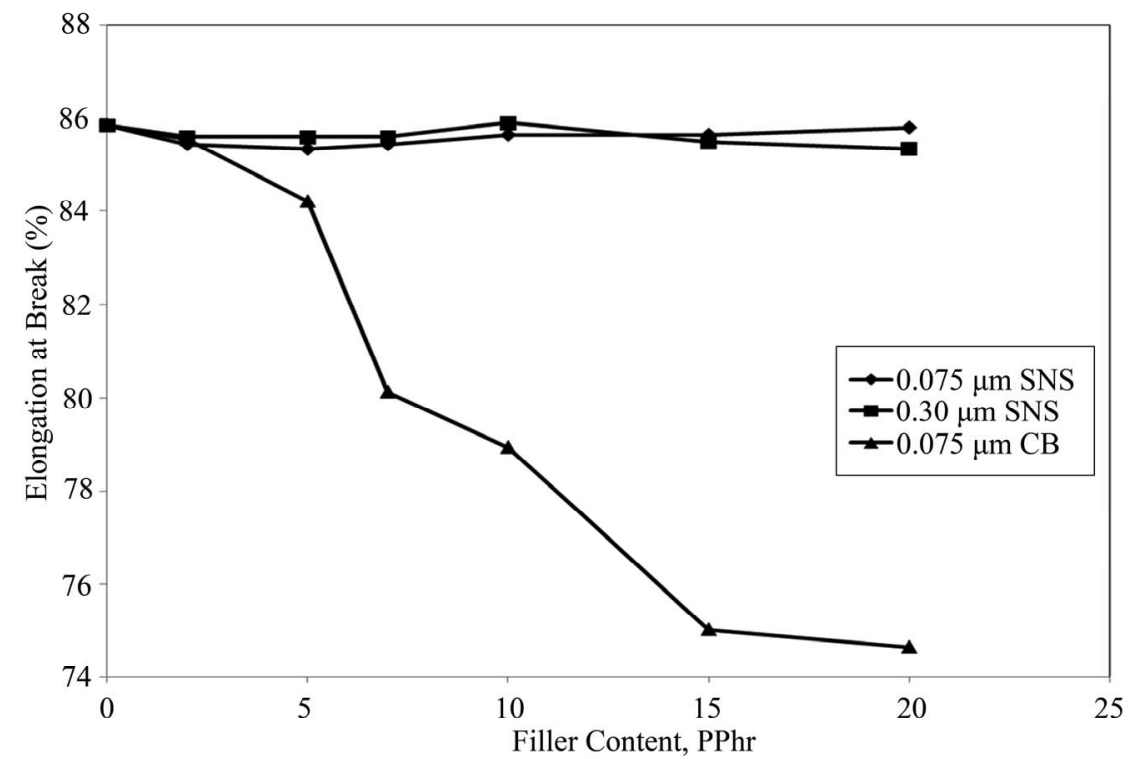

Figure 3. The effect of filler content and particle size on elongation at break of filled natural rubber.

filled rubber vulcanizate at the filler contents studied. Generally, the addition of fillers into natural rubber leads to decreases in EB of rubber vulcanizates, irrespective of whether the filler is reinforcing or inert [15]. The trend, decreases in EB with increasing filler content may be due to the non-stiffening of the rubber chains, and hence, non resistance to stretch when strain is applied. Figure $\mathbf{3}$ also shows that the EB of rubber vulcanizates of snail shell powder, particle sizes, 0.075 and $0.30 \mu \mathrm{m}$ are quite similar.

The resilience (\%) of filled and unfilled rubber vulcanizates is shown in Figure 4. Carbon black is observed to increase the heat build up in rubber vulcanizates within the filler content, 2 to $7 \mathrm{pphr}$ after which decreases in heat build up with increases in carbon black content is observed till the figure fell below the heat build up of unfilled rubber vulcanizate $(87.7 \%)$ at 20 pphr carbon black content.

Snail shell powder filled natural rubber is however observed to behave differently. The resilience of snail shell powder, particle size, $0.075 \mu \mathrm{m}$ filled natural rubber vulcanizate is observed to be unaffected with increases in filler content within the range, 2 to $10 \mathrm{pphr}$, and has the same value as the unfilled rubber vulcanizate. At 15 to 20 


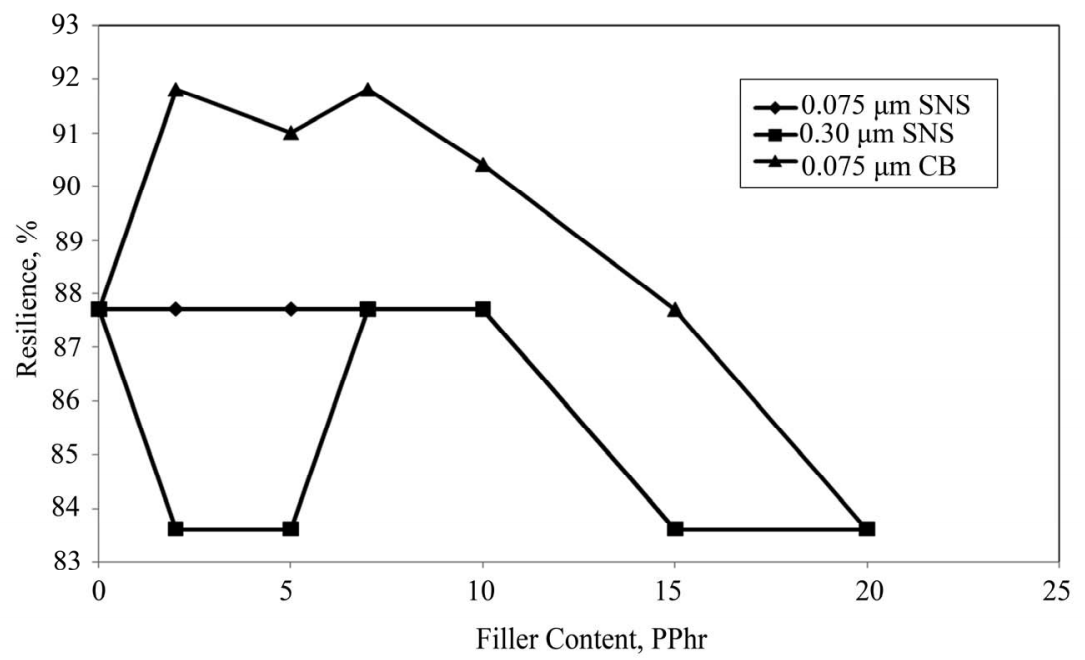

Figure 4. The effect of filler content and particle size on resilience of filled natural rubber.

pphr filler contents, the resilience of the rubber vulcanizates decreased to a content value of $83.6 \%$ in the two filler contents. For snail shell powder $(0.30 \mu \mathrm{m})$ filled natural rubber, the resiliences at 2 to $5 \mathrm{pphr}$, and 15 to 20 pphr filler contents have the same value $(83.6 \%)$, and which are lower than the resiliences at 7 to $10 \mathrm{pphr}$ filler contents. The smaller sized snail shell powder exhibited higher resilience when compared to the larger sized one within the filler contents, 2 to $7 \mathrm{pphr}$ after which both particle sizes exhibited similar resilience values.

As should be expected, the resilience of smaller sized snail shell powder filled natural rubber vulcanizates would have been greater than that of larger sized snail shell powder but this was not generally observed in this study. Heat generation in a rubber compound is not an intrinsic material property; it depends on the structure of filler particles, and also, on the nature of the crosslinks in the vulcanizate [21]. With decreasing particle size of the filler, the specific surface area would increase. This will lead to an increase in filler-filler, and polymer-filler interactions, thereby increasing the heat build-up. At high filler content (20 pphr), both carbon black and snail shell powder have the same resilience value in the vulcanizates; an indication that the resilience of natural rubber vulcanizates at high filler loadings is independent of the nature of the filler or filler particle size. Generally, carbon black showed high resilience values when compared to snail shell powder in the rubber vulcanizates.

Figure 5 shows the effect of filler content and particle size on the hardness of vulcanized natural rubber. The hardness of unfilled vulcanized natural rubber is 39 . The figure shows no appreciable increase in the hardness of vulcanized rubber with increasing snail shell powder content. A previous study [22] has reported a general increase in the hardness of vulcanized natural rubber with increases in filler content. At any snail shell powder content considered, there was no appreciabe affect of filler size on the hardness of vulcanized natural rubber. This may be an indication of low impact strength of the vulcanizates, and enhancement of abraision, and which makes snail shell powder to act as a non-reinforcing filler. Carbon black showed more improvement in the hardness of vulcanized natural rubber than snail shell powder. This can be attributed to the likely more uniform dispersion of carbon black in the polymer matrix as well as better carbon black-natural rubber interactions in the system.

The effect of filler content and particle size on the specific gravity of natural rubber vulcanizates is shown in Figure 6. Figure 6 shows a general continuous increase in specific gravity for all the compositions with increases in filler content in comparison to the unfilled natural rubber vulcanizate at any given filler particle size considered. However, at any given snail shell powder content considered, the specific gravity of the vulcanizates decreases with increase in the particle size of snail shell powder. The findings of this study are in agreement with the work of Mishra and Shimpi [19] who reported a general increase in the specific gravity of rubber vulcanizates with increases in filler contents. The increase in the specific gravity with a reduction in the filler particle size can be attributed to the filler size effect where the smaller sized filler is envisaged to be more uniformly dispersed in the rubber matrix, and which would keep the rubber chains intact on crosslinking. The increase in specific gravity of the vulcanizates was more pronounced for carbon black than for snail powder.

The greater increase in specific gravity shown by carbon black could be attributed to the better compatibility, and more uniform dispersion of carbon black in the rubber matrix. 


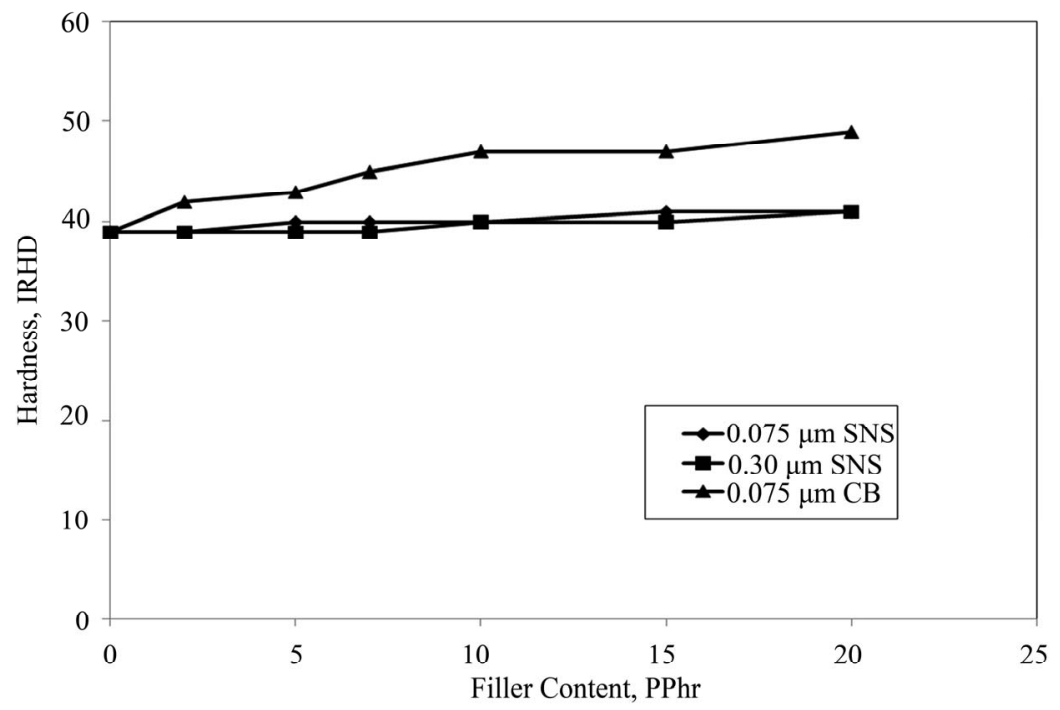

Figure 5. The effect of filler content and particle size on hardness of filled natural rubber.

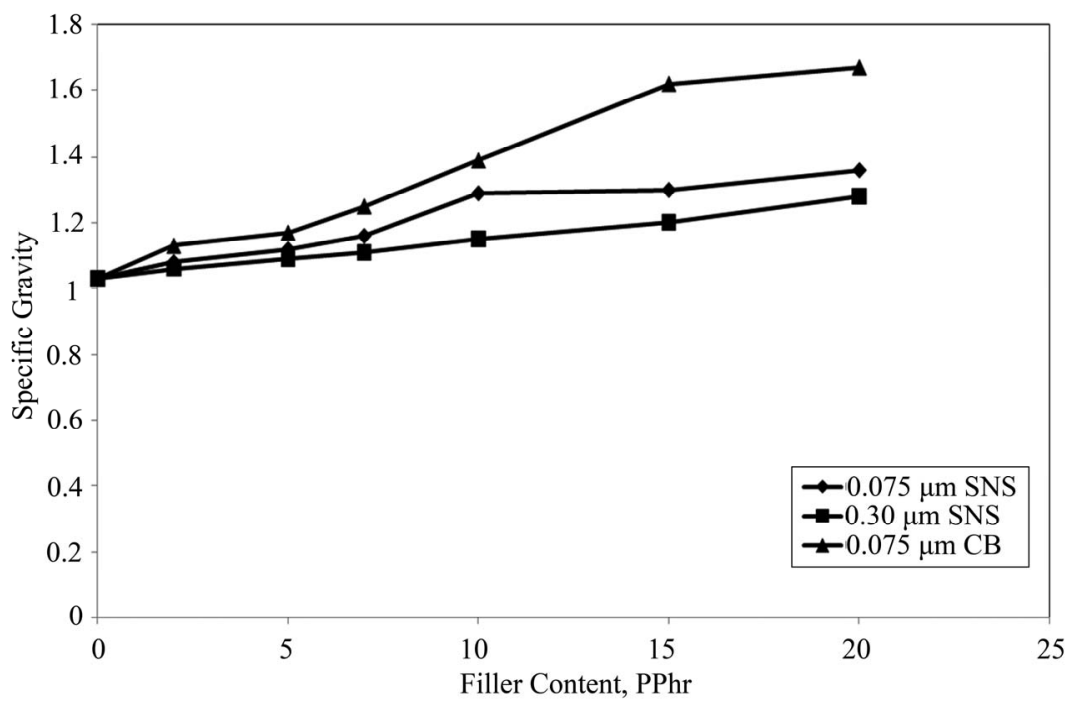

Figure 6. The effect of filler content and particle size on specific gravity of filled natural rubber.

The swelling indices of the different filler compositions (vulcanizates) in toluene at room temperature are shown in Figure 7. All the vulcanizates showed decreases in swelling index with increase in filler contents at the filler particle sizes considered. Also worthy to note is that the swelling index at a given snail shell powder content and different filler (SNS) particle sizes are very similar; an indication that the swelling index of the vulcaizates does not strongly depend on the snail shell powder particle size. The reduction in swelling index observed in this study with decreases in snail shell powder particle size may be due to the greater crosslinking of rubber since the envisaged uniform bring the chains closer, and keep them intact. Carbon black sobbed the least amount of toluene when compared to carbon black.
The rate of burning of different filled rubber vulcanizates is illustrated in Figure 8. The figure shows that at any given particle size of snail shell powder considered, the rate of burning of the vulcanizates was observed to decrease with increases in filler content at snail shell powder content above $5 \mathrm{pphr}$. In order words, the snail shell powder is inefficient as a filler in retarding the rate of burning of rubber vulcanizates at filler content less than 5 pphr. Carbon black was observed to reduce the rate of burning of rubber vulcanizates at all the filler contents investigated. It is important to note that the decreases in the rate of burning of snail shell powder filled rubber vulcanzates with increases in filler content and at any given filler particle size is very marginal, and may point to the fact that the flame retardant property of snail 


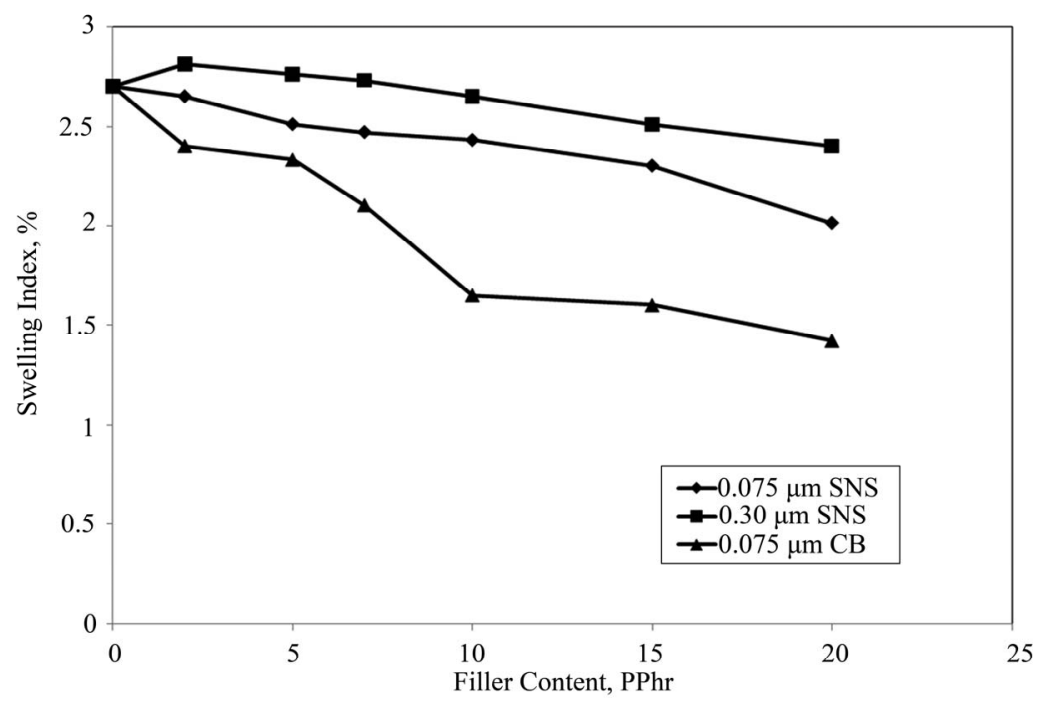

Figure 7. The effect of filler content and particle size on swelling Index of filled natural rubber.

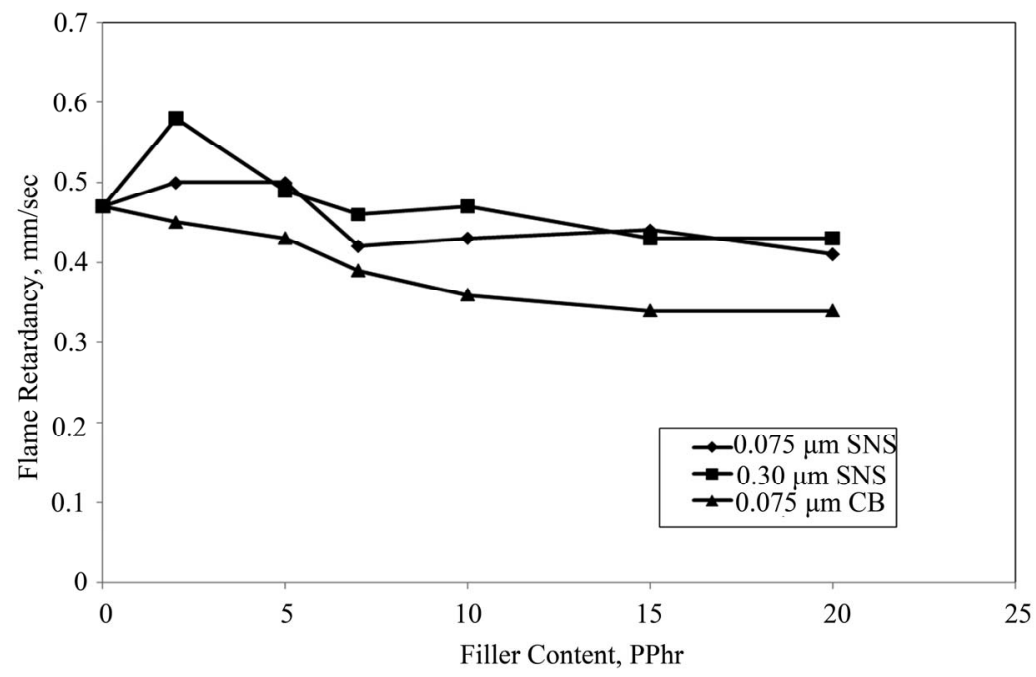

Figure 8. The effect of filler content and particle size on flame retardancy of filled natural rubber.

shell powder in the vulcanizate is not particularly good. Figure 8 also shows that the rate of burning of snail shell powder filled rubber vulcanizates decreases with decreases in filler particle size. This again is attributed to the envisaged greater dispersion of the smaller sized filler in the vulcanzates, and which resulted in greater absorption of energy, and hence, less tendency for the vulcanizates to burn.

This study shows that carbon black is superior to snail shell powder in retarding the rate of burning of rubber vulcanizates.

\section{Conclusions}

The use of snail shell powder as a filler in compounding natural rubber has been studied. The tensile strengths of snail shell powder (SNS) filled natural rubber vulcani- zates were found to be appreciably higher than that of unfilled rubber vucanizate at 2 pphr filler content. Carbon black, the reference filler, exhibited high tensile strengths in the vulcanzates and which were, in all cases, higher than those of snail shell powder filled rubber vulcanizates. The modulus of SNS filled rubber vulcanizates is always less than that of unfilled rubber vulcanizate at all the filler contents and particle sizes investigated. Carbon black was found to exhibit very high modulus in the natural rubber vulcanizates.

Carbon black was found to increase the hardness of vulcanized rubber more than snail shell powder, and this increased with increase in carbon black content. A general continous increase in specific gravity with increase in filler content was observed in this study for all the filled rubber vulcanizates. At any given snail shell pow- 
der content considered, the specific gravity of the vulcanizate decreased with increase in the particle size of snail shell powder. All the filled rubber vulcanizates showed decreases in swelling index with increase in filler content at the filler particle size considered. The rate of burning of snail shell powder filled rubber vulcanizates was observed to decrease with increase in the filler content at snail shell powder content above $5 \mathrm{pphr}$.

\section{REFERENCES}

[1] M. Arroyo, M. A. Lopez-Manchado and B. Herrero, "Organo-montmorillonite as Substitute for Carbon Black in Natural Rubber Compounds," Polymer, Vol. 44, No. 8, 2003, pp. 2447-2453. doi:10.1016/S0032-3861(03)00090-9

[2] H. Ismail, H. D. Rozman, R. M. Jaffri and Z. A. Mohd Ishak, "Oil Palm Wood Flour Reinforced Epoxidized Natural Rubber Composites: Effects of Filler Content and Size". European Polymer Journal, Vol. 33, No. 10-12, 1997, pp. 1627-1632. doi:10.1016/S0014-3057(97)00020-7

[3] L. Zhang, Y. Wang, V. Way, Y. Sin and D. Yu, "Morphology and Mechanical Properties of Clay/Styrene-Butadiene Rubber Nancomposites," Journal of Applied Polymer Science, Vol. 78, No. 11, 2000, pp. 1873-1878. doi:10.1002/1097-4628(20001209)78:11<1873::AID-APP 40>3.0.CO;2-8

[4] H. Zhang, Y. Wang, L. Zhang and J. Yang, "Preparation and Prcessing of Novel Polymer Materials," Journal of Applied Polymer Science, Vol. 97, No. 3, 2004, pp. 844-849. doi:10.1002/app.21797

[5] H. Zhang, Y. Wang, Y. Wu, L. Zhang and J. Yang, "Study on Flammability of Montmorillo Nite/Styrene-But-Adiene Rubber Nancomposites," Vol. 97, 2005, pp. 844-849.

[6] M. Zhao and Y. Xiang, "Natural Rubber Vulcanizate Reinforced by Modified Coalshale-Based Fillers," Journal of Applied Polymer Science, Vol. 93, No. 3, 2004, pp. 1397-1400. doi:10.1002/app.20506

[7] M. Kim, D. Kim, S. R. Chowdhury and G. Kim, "Melt-Compounded Butadiene Rubber Nancomposites with Improved Mechanical Properties and Abraision Resistance," Journal of Applied Polymer Science, Vol. 102, No. 3, 2006, pp. 2062-2066. doi:10.1002/app.23738

[8] J. Yang, M. Tian, Q. Jia, L. Zhang and X. Li, "Influence of Graphite Particle Size and Shape on the Properties of NBR," Journal of Applied Polymer Science, Vol. 102, No. 4, 2006, pp. 4007-4015.doi:10.1002/app.24844

[9] A. Ansarifar, S. F. Shiah and M. Bennett, "Optimizing the Chemical Bonding between Silanised Silica Nanofiller and Natural Rubber and Assessing Its Effects on the Properties of the Rubber," International Journal of Adhesion and Adhesives, Vol. 26, No. 6, pp. 454-463. doi:10.1016/j.ijadhadh.2005.06.008.

[10] H. Ismail, R. Nordin and A. M. Noor, "Cure Characteristics, Tensile Properties and Swelling Behaviour of Recycled Rubber Powder-Filled Natural Rubber Compounds,"
Polymer Testing, Vol. 21, No. 4, 2002, pp. 565-569. doi:10.1002/app.24844

[11] H. Osman, H. Ismail and M. Mustapha, "Effects of Maleic Anhydride Polypropylene on Tensile, Water Absorption, and Morphological Properties of Recycled Newspaper Filled Polypropylene/Natural Rubber Composites," Journal of Composite Materials, Vol. 44, No. 12, pp. 1477-1491. doi:10. 1177/0021998309359212, January, 2010.

[12] H. Ismail, A. Rusli, A. R. Azura and Z. Ahmad, "The Effects of Partial Replacement of Paper Sludge by Commercial Fillers on Natural Rubber Composites," Journal of Reinforced Plastics and Composites, Vol. 27. No. 16-17, November 2008, pp. 1877-1891. doi: $10.1177 / 0731684408088888$

[13] M. S. Sobhy and M. T. Tamman, "The Influence of Fibre Length and Concentration on the Physical Properties of Wheat Husk Fibre-Rubber Composites," Vol. 2010, No. 2010. doi:10. 1155/2010/528173.

[14] B. F. Adeosun, "Mechanical and Rheological Properties of Natural Rubber Composites Reinforced with Agricultural Waste," Nigerian Journal of Polymer Science and Technology, Vol. 1, No. 1, 2002, pp. 58-62.

[15] F. E. Okieimen and J. E. Imanah, "The Characterization of Agricultural Waste Products as Fillers in Natural Rubber Formulations," Nigerian Journal of Polymer Science and Technology, Vol. 3, No. 1, 2003, pp. 210-216.

[16] N. Lopattananon, K. Panawarangkul, K. Sahakaro and B. Ellis, "Performance of Pineapple Leaf Fibre-Natural Rubber Composites: The Effect of Fibre Surface Treatments," Journal of Applied Polymer Science, Vol. 102, 2006, pp. 1974-1984.

[17] I. O. Igwe, "Studies on the Properties of Polypropylene Filled with Agricultural and Domestic Wastes," Journal of Research in Engineering, Vol. 4, No. 2, 2007, pp. 9-13.

[18] A. S. M. Salenddin and K. M. J. Wilbur, "Chemical Composition of Snail Shell," Journal of Zoology, Vol. 47, 1969, pp. 51-55.

[19] S. Mishra and N. G. Shimpi, "Mechanical and Flame Retardant Properties of Styrene-Butadiene Rubber Filled with $\mathrm{CaCO}_{3}$ as a Filler and Linseed Oil as an Extender," Journal of Applied Polymer Science, Vol. 98, No. 6, 2005, pp. 2563-2571. doi:10.1002/app.22458

[20] A. Ahmad, D. H. Mohd and I. Abdullah, "Mechanical Properties of Filled NR/LLDPE Blends," Iranian Polymer Journal, Vol. 13, No. 3, 2004, pp. 173-178.

[21] V. Sridhar, R. N. P. Choudhary and D. K. Tripathy, "Effect of Carbon Black on Relaxation Phenomenon of Chlorobutyl Vulcanizates," Journal of Applied Polymer Science, Vol. 102, No. 2, 2006, pp. 1809-1820. doi:10.1002/app. 23640

[22] R. A. Kruger, M. Hovy and D. Wardle, "The Use of Fly Ash Fillers in Rubber," International Ash Utilization Symposium, Centre for Applied Energy Research, University of Kentucky, 1999, p. 72. 